\title{
A POLÍTICA CRIMINAL DE INTERVENÇÃO DO ESTADO NA APLICAÇÃO DAS PENAS E A OBRA VIDAS SECAS, DE GRACILIANO RAMOS
}

\section{CRIMINAL POLICY OF STATE INTERVENTION IN THE APPLICATION OF PENALTIES AND THE BOOK "VIDAS SECAS" BY GRACILIANO RAMOS}

\author{
${ }^{1}$ Jacyara Farias Souza \\ ${ }^{2}$ Jônica Marques Coura Aragão
}

\section{RESUMO}

Em tempos de violência generalizada, que acaba por provocar uma reação intensa por parte do Estado, que na tentativa de solucionar a questão da insegurança, emprega-se, em regra, o Direito Penal em suas diversas perspectivas de política criminal. O presente trabalho tem como objetivo analisar duas dessas vertentes: o Direito Penal Mínimo e o Direito Penal Máximo, verificando o seus enfoques e, principalmente, a forma que cada vertente se aplica aos casos concretos. Para tanto, se emprega o método dedutivo e a técnica de pesquisa bibliofráfica. Realiza-se a intertextualidade com a literatura brasileira através da obra Vidas Secas de Graciliano Ramos, especialmente com o recorte destacado no capítulo do Soldado Amarelo, no contexto relacionado ao personagem principal, Fabiano, que nos remete a um contexto crítico da aplicação do Direto Penal Brasileiro. Pretende ainda, problematizar as eventuais mudanças que ocorreram desde a época em que a história se passa e a época atual priorizando observar as mudanças efetivamente implantada.

Palavras-chave: Políticas criminais, Vidas secas, Intertextualidade, Direito penal

\begin{abstract}
In times of widespread violence, which ultimately provoke a strong reaction from the State, that in an attempt to resolve the issue of insecurity, employs, as a rule, criminal law in its various perspectives of criminal policy. This study aims to examine two of these theories: the Criminal Law Minimum and the Criminal Law Maximum, checking their approaches and especially the way that each theory is applied to concrete cases. Therefore, we use the deductive method and bibliographic research technique. We execute an intertextuality with Brazilian literature through the book "Vidas Secas" by Graciliano Ramos, especially with the part highlighted in the chapter "Soldado Amarelo", in the context related to the main character "Fabiano", which brings us to a context critical application of Brazilian Criminal Law. We also intend to discuss any changes that have occurred since the time the story had taken place and the current time prioritizing observe the effective implemented changes.
\end{abstract}

Keywords: Criminal policies, Vidas secas, Intertextuality, Criminal law

\footnotetext{
${ }^{1}$ Doutora em Ciências Jurídicas e Sociais pela Universidad del Museo Social Argentino - UMSA, Buenos Aires (Argentina). Professora Adjunto-I da Universidade Federal de Campina Grande - UFCG, Paraíba (Brasil). E-mail: jacyfarias@gmail.com

${ }^{2}$ Doutora em Recursos Naturais pela Universidade Federal de Campina Grande - UFCG, Paraíba (Brasil). Professora de Direito pela Universidade Federal de Campina Grande - UFCG, Paraíba (Brasil). E-mail: jonicamca@gmail.com
} 


\section{INTRODUÇÃO}

Em tempos de intenso entrelaçamento social observa-se a sobrecarga generalizada da atividade judicial em todos os campos jurídicos, mas, principalmente, no Sistema Penal brasileiro por ser utilizado como principal meio de punição das atitudes ilícitas que acarretam conflitos humanos. Essa postura que o Direito Penal vem assumindo, tem prejudicado o cumprimento das suas regras básicas, que visam garantir uma punição adequada para cada tipo de ação e consequente proteção a análise individual dos acusados.

A superlotação desse sistema carcerário tem sido motivo de muitos prejuízos para a sociedade brasileira, porque dificulta a realização das suas funções com qualidade. Não há condições mínimas de se cumprir a pena, os agentes não possuem a formação adequada e acabam agindo por ideologia e vontade própria e o Estado ainda encarcera ostensivamente, sem se preocupar com a situação precária em que o sistema se encontra.

O problema não é recente, a propósito, neste aspecto, encontra-se na obra "Vidas Secas", o fiel retrato do descaso Estatal, quando analisada a postura do agente em utilizar dos seus poderes para abordar um cidadão iletrado, se indispor contra ele e levá-lo para o cárcere. A concomitância entre a análise das características práticas da aplicação do Direito Penal e o que acontece na obra literária de Graciliano Ramos, mostra a concretude da defasagem desse sistema.

O problema é grave, mas, a discussão dos seus efeitos é mínima; e a busca de soluções é remota. Por isso, observa-se a necessidade de uma análise dos institutos jurídicos diretamente ligados à resolução dos problemas da justiça penal brasileira, para que com argumentos concretos seja possível exigir do Estado uma solução. É utilizando a literatura brasileira que se pretende analisar o retrato do caso concreto e contrapô-lo ao que já existe de garantia de direitos, para exigir o seu cumprimento.

\section{REFERENCIAL TEÓRICO}

Sobre o problema do emprego do direito penal e, consequentemente, do encarceramento, muito se tem discutido em bases teóricas no mundo inteiro. Não há consenso, face à intensa polêmica que o problema representa. Muitas linhas de política criminal se apresentam na tentativa de melhor direcionar as posturas estatais e alcançar soluções ao complexo problema a ser equacionado. Nesse aspecto é que se debruça a análise 
duas das mais pertinentes e antagônicas propostas para o tratamento jurídico-penal da temática.

\subsection{DIREITO PENAL MÁXIMO}

O Direito Penal Máximo trata-se de uma política criminal de grande repercussão nos Estados Unidos da América na década de 1970 e foi ganhando força na Europa com o fracasso do Estado de Bem Estar Social. Este foi disseminado através do "Movimento da Lei e da Ordem" sendo o alemão Ralf Dahrendorf um dos seus criadores, que com a força da mídia foi ganhando espaço e incentivando os ordenamentos jurídicos a efetivar um moviemnto de expansão do Direito Penal.

Jesus (2007) bem retrata a verdadeira intenção do Movimento da Lei e da Ordem, quando afirma que um dos princípios do "Movimento de Lei e Ordem" é separar a sociedade em dois grupos: o primeiro, composto de pessoas de bem, merecedoras de proteção legal; o segundo, de homens maus, os delinquentes, aos quais se endereça toda a rudeza e severidade da lei penal.

Afirma, ainda, o autor que quando adotou essas regras, o Projeto Alternativo alemão de 1966 dizia que a pena criminal era "uma amarga necessidade numa comunidade de seres imperfeitos". É o que está acontecendo no Brasil. Cristalizou-se o pensamento de que o Direito Penal pode resolver todos os males que afligem os cidadãos (homens bons), exigindose a definição de novos delitos e o agravamento das penas cominadas aos já descritos, tendo como destinatários os criminosos (homens maus), dando enorme valor aos delitos de maior gravidade, como assaltos, latrocínios, sequestros, homicídios, estupros.

A frequência do noticiário desses crimes fomenta a síndrome da vitimização. A população termina por acreditar que, a qualquer momento, o cidadão pode ser vítima de um ataque criminoso, gerando a idéia da urgente necessidade da agravação das penas e da definição de novos tipos penais, em busca de garantir a tranquilidade.

O que na verdade acontece a partir da adoção dessa teoria é a exaltação do Sistema Penal acarretando punições indiscriminadas; partindo para o ideal do senso comum, onde se acredita que punir mais é punir melhor. Esse senso comum fortalecido midiaticamente, não dimensiona adequadamente o perigo que esta postura pode ocasionar ao pretender resolver o problema da criminaidade com o encarceramento dos autores de todo e qualquer tipo de infração penal cometida. 
A base teórica dessa postura remete ao Funcionalismo desenvolvido, principalmente, por Günther Jakobs. Ele segue a linha da norma e do funcionamento do sistema como um valor em si mesmo, com isso, fortalece cada vez mais o poder Estatal que se legitima por suas açãoes, em regra, autoritárias; não se adaptando a ideologia mais aberta do Estado Democrático de Direito que é conferir ao povo o poder, deixando o Estado como entidade subsidiária de governo.

O auge do Movimento da Lei e da Ordem no Brasil se deu logo após a instituição da Constituição Federal de 1988 e como bem ressalta Biachinni (2013):

Este Movimento passa a dominar o cenário político-social, principalmente nesta década, tendo sido responsável pela edição de inúmeras leis, cujas características principais repousam na ideia de que o Direito penal deve representar um instrumento de combate à criminalidade, sendo que para tal há que se instituir uma ordem penal o máximo possível repressiva, reduzindo cada vez mais benefícios de ordem penal e processual penal.

Os adeptos dessa teoria de expansão defendem veementemente a pena como única saída para resolver o problema da criminalidade no país. São eles os maiores defensores do estilo de penalização severa, como sendo a pena de morte e a prisão perpétua as melhores formas para separar do convívio social as pessoas de bem, do inimigo que é corrompido e insiste em atrapalhar a ordem da sociedade. Por isso nos Estados Unidos a definiu em uma ramificação ideológica da Política Tolerância Zero como define Wacquant (2001, p.17):

$\mathrm{Na}$ realidade a política de tolerância zero, surgiu não com o intuito primordial de diminuir a criminalidade, mas de refrear a insegurança das classes altas e médias da sociedade, tirando os "excrementos humanos" de suas vista recriminando severamente delitos menores tais como embriaguez, a jogatina, a mendicância.

Diante disso percebe a gravidade de aplicação desta teoria e a segregação social que ela acarreta. Porque seus adeptos, tal qual praticado no Nazismo, se sentem superiores ao outros seres e para minorizá-los ainda mais excluem as garantias penais e processuais que possuíam, tendo a mídia grande influencia por causar nas pessoas o ódio e incentivá-las a praticar atitudes radicais e cruéis com os que muitas vezes nem são os reais culpados.

A penalização repressiva tende a excluir do ordenamento jurídico-penal as penas alternativas por considerarem que elas são um erro intelectual, como aborda Ralf Dahrendorf, 
e podem gerar o sacrifício de uma sociedade inteira por querer amenizar a punição de um individuo criminoso e além de desestimular os que lutam pela liberdade, irá colocá-los em um risco muito maior.

Assim o que realmente importa, é utilizar o Direito Penal enquanto prima ratio, sendo a aplicação da pena a primeira medida a ser tomada pelo Estado para ser utilizada como forma de coerção, educação e repressão imediatas, sendo a primeira medida a ser tomada pelo Estado. Deve ele utilizar “o corte do mal pela raiz", que pressupõe punir o delito praticado por menos e insignificante que ele seja para que este individuo não tenha, dentro da cadeia, a oportunidade de cometer crimes maiores, achando pois que o poder estatal, com o encarceramento, corrige a vontade viciada do "criminoso", não voltando o mesmo a infringir a lei.

O principal resultado dessa política de coerção dura e imediata é a hipertrofia do Sistema Penitenciário em todos os lugares em que se adota tal forma de punição, mas principalmente, nos países onde o déficit desse sistema é maracado pela ineficiência estatal, especialmente em sua esfera administrativa.

O aumento de penas, na prática, acaba se caracterizando como apenas uma resposta para a sociedade que exige do governo essa forma solução das demandas criminais. Para Pavarini (2011), o que preocupa é o fato de que, na realidade, esse aumento de pena e a construção de mais presídios não resolvem o problema real da criminalidade. É sabido que a construção de mais presídios acaba apenas por representar mais prisões e mais população carcerária.

Bauman (1999, p.127) confirma a manobra do poder estatal para dar a resposta que o que a sociedade quer com isso é se fortalecer diante dos seus eleitores:

A construção de novas prisões, a redação de novos estatutos que multiplicam as infrações puníveis com prisão e o aumento das penas, todas essas medidas aumentam a popularidade dos governos, dando-lhes a imagem de severos, capazes, decididos e, acima de tudo, a de que "fazem algo" não apenas explicitamente pela segurança individual dos governados mas, por extensão, também pela garantia e certeza deles e fazê-lo de uma forma altamente dramática, palpável, visível e tão convincente.

Há pesquisas que confirmam a ineficácia do sistema prisional e a hipertrofia do mesmo. O que significa que a recorrente prisão de muitos indivíduos não foi capaz de diminuir a criminalidade; tendo-se constatado, muitas vezes, casos de reincidência e também 
de novos criminosos o que demonstra que a forma de coerção não amedrontou os que ainda não haviam sido contaminados com o mundo do crime.

Assim, o Instituto de Defesa do Direito de Defesa (IDDD), teve disponibilizado pela Comissão Interamericana de Direitos Humanos (CIDH) o informe: Informe sobre el uso de la prisión preventiva en las Américas, que determina o Brasil com a segunda maior lotação carcerária da região ficando atrás dos Estados Unidos da América que assume a liderança. $\mathrm{O}$ informe ainda apresenta uma tabela que trata da proporção geral das pessoas em prisão preventiva, da América Latina, que segue abaixo:

Cuadro 1: proporción general de personas en prisión preventiva.

\begin{tabular}{|c|c|c|c|c|}
\hline Estado & $\begin{array}{l}\text { Número de } \\
\text { personas privadas } \\
\text { de libertad }\end{array}$ & $\begin{array}{c}\text { Número/porcentaje de } \\
\text { procesados }\end{array}$ & $\begin{array}{l}\text { Número/porcentaje } \\
\text { de condenados }\end{array}$ & $\begin{array}{l}\text { Fecha de la } \\
\text { información }\end{array}$ \\
\hline Bolivia $^{65}$ & 13,654 & $\begin{array}{l}11,410(84 \%) \\
\text { Preventivos }\end{array}$ & $\begin{array}{l}2,244(16 \%) \\
\text { Sentenciados }\end{array}$ & A octubre de 2012 \\
\hline Brasil $^{66}$ & $\begin{array}{l}549,577 \\
\text { (508,357 en } \\
\text { custodia del } \\
\text { Sistema } \\
\text { Penitenciario y } \\
41,220 \text { custodiados } \\
\text { por las Policía } \\
\text { Judicial de los } \\
\text { estados (Secretarias } \\
\text { de Seguridad } \\
\text { Pública). }\end{array}$ & $\begin{array}{l}\text { 191,024 (37.6\%) } \\
\text { (De los } 508,357 \\
\text { custodiados por el } \\
\text { Sistema Penitenciario) }\end{array}$ & $\begin{array}{l}317,333(62.4 \%) \\
\text { (De los } 508,357 \\
\text { Custodiados por el } \\
\text { Sistema Penitenciario) }\end{array}$ & A junio de 2012 \\
\hline Chile & 53,171 & $\begin{array}{l}10,823(20.4 \%) \\
\text { Sin sentencia } \\
\text { (detenidos, procesados } \\
\text { imputados) }\end{array}$ & $\begin{array}{l}42,348(79.6 \%) \\
\text { Con sentencia firme }\end{array}$ & $\begin{array}{l}\text { Al } 31 \text { de julio de } \\
2012\end{array}$ \\
\hline Colombia & 113,884 & $\begin{array}{l}34,571(30.35 \%) \\
\text { Sindicados }\end{array}$ & $\begin{array}{l}79,313(69.65 \%) \\
\text { Condenados }\end{array}$ & $\begin{array}{l}\text { Al } 31 \text { de diciembre } \\
\text { de } 2012\end{array}$ \\
\hline Costa Rica & 13,017 & $\begin{array}{l}3,248(25 \%) \\
\text { Indiciados }\end{array}$ & $\begin{array}{l}9,769(75 \%) \\
\text { Sentenciados }\end{array}$ & A octubre de 2012 \\
\hline
\end{tabular}




\begin{tabular}{|c|c|c|c|c|}
\hline El Salvador & 26,883 & $\begin{array}{l}6,459(24 \%) \\
\text { Procesados }\end{array}$ & $\begin{array}{l}20,424(76 \%) \\
\text { Condenados }\end{array}$ & $\begin{array}{l}8 \text { de octubre de } \\
2013\end{array}$ \\
\hline Ecuador & $\begin{array}{l}19,177 \\
\text { En centros penales } \\
\text { administrados por } \\
\text { el Ministerio de } \\
\text { Justicia y Derechos } \\
\text { Humanos }{ }^{67} \text {. }\end{array}$ & $\begin{array}{l}9,409 \text { ( } 49 \%) \\
\text { No sentenciados } \\
\text { ( } 8,630 \text { procesados, } \\
377 \text { contraventores, } \\
402 \text { con medidas de } \\
\text { apremios). }\end{array}$ & $\begin{array}{l}9,768 \text { ( } 51 \%) \\
\text { Sentenciados } \\
(4,732 \text { con sentencia } \\
\text { ejecutoriada ( } 25 \%) \text { y } \\
5,036 \text { en impugnación } \\
\text { o modificación). }\end{array}$ & $\begin{array}{l}\text { Al } 1 \text { de agosto de } \\
2012\end{array}$ \\
\hline \multicolumn{5}{|l|}{ El Salvador } \\
\hline Guatemala & 14,635 & $\begin{array}{l}7,357 \text { (50.3\%) } \\
\text { Preventivos }\end{array}$ & $\begin{array}{l}7,278(49.7 \%) \\
\text { Condenados }\end{array}$ & A octubre de 2012 \\
\hline Honduras & 12,407 & $\begin{array}{l}6,064(48.9 \%) \\
\text { Procesados }\end{array}$ & $\begin{array}{l}6,343(51.1 \%) \\
\text { Condenadas }\end{array}$ & A abril de 2013 \\
\hline Nicaragua & 9,168 & $\begin{array}{l}1,127(12.3 \%) \\
\text { Acusados }\end{array}$ & $\begin{array}{l}8,041(87.7 \%) \\
\text { Condenados }\end{array}$ & $\begin{array}{l}\text { Al } 31 \text { de diciembre } \\
\text { de } 2012\end{array}$ \\
\hline Panamá & 14,521 & $\begin{array}{l}9,443 \text { (65\%) } \\
\text { En proceso } \\
\text { A órdenes del } \\
\text { Ministerio Público: } \\
\text { 5,592; a órdenes del } \\
\text { Org. Judicial: } 3,135 ; \\
\text { Otros: } 716 \text {. }\end{array}$ & $\begin{array}{l}5,078(35 \%) \\
\text { Condenados } \\
\text { Delitos: } 4,421 \\
\text { Faltas: } 339 .\end{array}$ & A octubre de 2012 \\
\hline
\end{tabular}

\begin{tabular}{|c|c|c|c|c|}
\hline Paraguay & 7,901 & $\begin{array}{l}5,780(73.1 \%) \\
\text { Procesados }\end{array}$ & $\begin{array}{l}2,126(26.9 \%) \\
\text { Condenados }\end{array}$ & $\begin{array}{l}\text { Al } 23 \text { de septiembre } \\
\text { de } 2012\end{array}$ \\
\hline Perú & 58,681 & $\begin{array}{l}34,508(58.8 \%) \\
\text { Procesados }\end{array}$ & $\begin{array}{l}24,173(41.2 \%) \\
\text { Sentenciados }\end{array}$ & $\begin{array}{l}\text { Al } 31 \text { de julio de } \\
2012\end{array}$ \\
\hline Uruguay & 9,330 & $\begin{array}{l}6,065(65 \%) \\
\text { Prisión preventiva }\end{array}$ & $\begin{array}{l}3,265 \text { ( } 35 \%) \\
\text { Condenados } \\
\text { S. } 19 \text { Instancia: } 535 \\
\text { S. } 2^{\circ} \text { Instancia: } 2,924\end{array}$ & $\begin{array}{l}\text { Al } 31 \text { de julio de } \\
2012\end{array}$ \\
\hline Venezuela & 36,236 & $\begin{array}{l}18,735 \text { (52\%) } \\
\text { Detención preventiva } \\
\text { (Procesados) }\end{array}$ & $\begin{array}{l}17,501(48 \%) \\
\text { Con sentencia firme } \\
\text { (Condenados) }\end{array}$ & $\begin{array}{l}\text { Al cierre del primer } \\
\text { semestre de } 2012 \text {. } \\
\text { Estas cifras } \\
\text { corresponden } \\
\text { especificamente al } \\
\text { universo de } \\
\text { reclusos asistidos } \\
\text { por la Defensa } \\
\text { Pública. }\end{array}$ \\
\hline
\end{tabular}

A pior parte dessa hipertrofia ineficaz do sistema, ainda fica por conta do altíssimo número de prisões processuais, isto é, as prisões efetuadas antes do julgamento final do processo, especialmente as prisões preventivas, que sobrecarregam ainda mais o sistema e ferem a base principiológica que deveria reger o processo em toda a sua extensão.

As evidências apontam para o fato de que os números exorbitantes de prisão, principalmente no Brasil, acontecem por da política criminal do Direito Penal Máximo e que, mesmo aplicada sistematicamente, hoje não produz mudanças efetivas na sociedade, pois ainda existem criminosos e a pena mais aplicada ainda é, a todo custo, a pena privativa de liberdade, mesmo com a consciência da sua falta de eficácia. 
Paralelo a isso, verifica-se uma vertente viável que se prolifera com vigor aqui no Brasil é o fato desse país ser adepto a políticas inovadoras que são empreendem esforços visando à implementação de políticas fomentadoras do Direito Penal Mínimo.

\subsection{DIREITO PENAL MÍNIMO}

Assim como o Direito Penal Máximo, o Direito Penal Mínimo se trata de uma política criminal de grande relevância no cenário social, principalmente, no atual que a cada vez mais visa garantir os direitos da pessoa humana. As vertentes abordadas pelo Direito Penal Mínimo e Máximo são diametralmente opostas, pois enquanto à primeira visa à aplicação da pena como ultima ratio, ou seja, em último caso, quando não houver mais jeito é que se decreta a forma privativa de liberdade como punição; a segunda defende como já abordada, anteriormente, a prima ratio que consiste na aplicação da pena em primeiro lugar, para que depois possa ser analisada a eficiência de outros meios punitivos, se é que eles são considerados por ela.

A ultima ratio significa ainda que a intervenção do Direito Penal deve ser mínima, só atuando este, quando os outros ramos do Direito não forem capazes de proteger os bens jurídicos em conflito. Ela limita e orienta o poder incriminador do Estado, e permite que ele tipifique uma conduta quando aquela for a única alternativa para proteger o bem, devendo ele ser de extrema relevância.

O Estado Democrático de Direito em que vivemos em sua conjuntura atual e pelos princípios constitucionais adotados tem ligação direta com o Direito Penal Mínimo, por ser esta a corrente que prima pela defesa desses princípios e coloca o cumprimento deles em prática, por priorizar análise do caso concreto e evitar ao máximo que formas radicais prevaleçam na punição dos indivíduos. Os princípios base que se correspondem são, principalmente o da dignidade da pessoa humana, da insignificância, da intervenção mínima, dentre outros.

É, pois, prioridade dessa corrente da política criminal a defesa da descriminalização de tipos penais que não ferem diretamente a proteção de bens jurídicos de alta relevância, verdadeiro âmbito de atuação do Direito Penal. Como defende Callegari (1998), a manutenção dos tipos incriminadores de pouca relevância, só atrapalha a atividade policial que fica perdendo tempo com bagatelas e a atividade criminal que vive com seus juizados sobrecarregados de processo, dificultando o andamento das demandas essenciais, pela 
presença de outras tantas que seriam dispensáveis. Como ainda defende Callegari (1998,p.478):

Desde muito assistimos sua aplicação e, nosso estado, mantendo a tradição de vanguarda no panorama jurídico nacional, já as tem utilizado em larga escala, proporcionando que muitos apenados, ao invés de superlotarem os presídios cumpram suas penas em regime de liberdade, exercendo atividades laborais junto a empresas e instituições integrantes ou não do governo.

O Garantismo Penal, principalmente, o idealizado por Luigi Ferrajoli, é uma teoria que se encaixa e complementa o Direito Penal Mínimo. Assim como dispõe Duarte Neto (2006) ao asseverar que o garantismo penal não se configura como uma doutrina distante de ser efetivamente concretizada no mundo jurídico atual, pois existem modernamente movimentos penais e criminológicos que ostentam a essência desse tirocínio, sendo a escola do direito penal mínimo seu maior representante entre seus defensores.

$\mathrm{Na}$ perspectiva do autor, o alcance dessa teoria seria a eficácia do direito penal no mundo contemporâneo, enfrentando, sobremaneira, a atuação do Direito Penal Simbólico, atenuando os efeitos do chamado Direito Penal do Inimigo.

A intervenção estatal na vida dos cidadãos deve possuir um caráter subsidiário e fragmentário, como prega tanto o Direito Penal Mínimo, como o Garantismo Penal, ele retrata muito bem a particularidade desse caráter. Nesse sentido dispõe Ferrajoli (2006, p. 383):

A justiça penal, com o caráter inevitavelmente desonroso de suas intervenções, não pode ser incomodada e, sobretudo, não pode incomodar os cidadãos por fatos de escasso relevo, como o são a maior parte dos atualmente castigados com simples multas.

O minimalismo penal reflete o abolicionismo moderado e que garante "mínimas intervenções, com máximas garantias” é o que defende Alessandro Baratta (2004, p.299.), sendo ele um elaborador de destaque da teoria minimalista.

O modelo que o Direito Penal Mínimo oferta, é ideal, se bem aplicado, para o Estado Democrático de Direito. Contudo, no Brasil, o hiperpunitivismo tem sido cada vez mais utilizado, quando se deveria diminuir a sua atuação para que as punições fossem mais justas e que o gasto Estatal fosse consideravelmente menor. O Brasil enfrenta, hoje, muitos problemas 
com a superlotação das penitenciárias por ter adotado como principal política de controle da criminalidade, aplicação da pena privativa de liberdade.

Autores que defendem o Direito Penal Mínimo são adeptos do caráter subsidiário do Direto Penal que se resume em cumprir as competências de cada ramo que esteja ao dispor do Estado, não sobrecarregando assim o Direito Penal e dando um caráter secundário a aplicação da pena.

Consiste, basicamente, em duas formas: uma externa e outra interna. A primeira irá recorrer aos outros ramos do Direito que possam solucionar estes problemas, ou até recorrer as formas de controle não formais, como a conciliação. A forma interna prevê a entrada no sistema penal mas a controla a partir do princípio da insignificância que livra os casos de menor potencial ofensivo de uma pena privativa de liberdade e os pune de acordo com o seu feito, sem maiores prejuízos para a sociedade, nem para o Estado.

Desde a validade da nova Parte Geral do Código Penal e da entrada em vigor da Constituição Federal de 1988, que prática dos princípios como Dignidade da Pessoa Humana, Insignificância e da Intervenção Mínima, tem sido exigida pela sociedade e reafirmada sua importância para a construção de uma sociedade plena.

Esses princípios se encaixam perfeitamente com a execução de um Direito Penal Mínimo que respeita a dignidade humana quando analisa o caso concreto para aplicação justa de punição, a insignificância quando pondera que determinadas infrações não merecem atenção e gasto exacerbados e podem se resolver sem envolver a Justiça Penal e a privação da liberdade e ainda, a intervenção mínima quando presa por soluções alheias a intervenção do Direito Penal facilitando até o processo de recuperação do próprio individuo e de diminuição de gasto do dinheiro público.

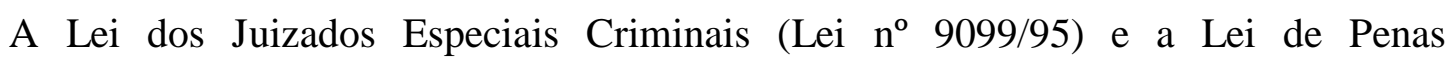
Alternativas (Lei $n^{\circ}$ 9.714/98) são exemplos concretos da intervenção mínima e possuem como objetivo principal o otimização dos presídios brasileiros e a aplicação de penas alternativas para infrações que não possuem ofensividade relevantes, pois para pena privativa de liberdade só devem ser submetidas infrações graves, contra direitos relevantes e essenciais da sociedade e quando não se visualiza outra maneira coercitiva.

Pode-se perceber nitidamente, que já há mecanismos para deter essa intervenção máxima do Estado, mas cada vez mais ele se insere na vida social, e mesmo com avanços consideráveis no ordenamento jurídico, o Estado continua achando que resolverá o problema da sociedade com o encarceramento dos indivíduos. Especialmente, e em maior número de prisões, dos indivíduos mais fragilizados socialmente. 


\section{VIDAS SECAS: CONTEXTUALIZANDO A INTERFACE PROPOSTA}

A seca de antes, é a seca de hoje. E não se traduz somente em seca hídrica; antes de tudo, é seca de justiça social. A obra trabalhada foi escrita por Graciliano no ano de 1938, ano em que se instaurou o Estado Novo de Getúlio Vargas. No enredo da obra conta-se a história de uma família de retirantes que, devido à seca, são obrigados a migrar de um lugar para outro em busca de água, alimento e condições dignas de sobrevivência. Embora tenha sido escrita há muitos anos, relata uma realidade atual, pois mesmo diante das evoluções obtidas com o passar do tempo, ainda se constata sofrimento e isolamento por causa da seca e da falta de inserção social de determinadas pessoas.

A história possui seis personagens que são: Fabiano, o chefe da família de retirantes, um vaqueiro que não tem o dom da oratória, de pouco entendimento e que pela sua brutalidade se autocompara a um bicho; sua esposa Sinhá Vitória, uma mulher de garra que possui a inteligência necessária para fazer cálculos e não permitir que enganem ainda mais Fabiano; os dois filhos, o mais velho e o mais novo; a cachorra Baleia que é a mascote da família e durante muito tempo é quem caça a presa para alimentá-los e o Soldado Amarelo que aparece na história por prender Fabiano após uma pequena discussão.

No decorrer da narrativa a família passa por muitas necessidades; não possuindo o básico para a sobrevivência, o sonho da vida de Sinhá Vitória é uma cama de tiras de couro para dormir. Compõem uma família muito humilde, que não encontra no Estado o apoio que necessita para não passar por tantas necessidades. $\mathrm{O}$ representante estatal mais próximo a eles é o Soldado Amarelo que utiliza do seu poder não para imprimir justiça, mas para oprimir e induzir que os cidadãos cometam determinadas infrações para posteriormente, puni-los.

O autor retrata muito bem a inveja e a admiração que Fabiano apresenta por seu Tomás da Bolandeira, por ele ser um homem letrado, que possui o dom das palavras e mesmo sendo possuidor de conhecimento e sabedoria, pela crueldade da seca, teve que se retirar do local em que viviam para que não morresse sem água e sem comida.

Mas, por diversas vezes, Fabiano acredita que se tivesse o mesmo conhecimento de seu Tomás, não passaria por metade das dificuldades que enfrenta. $\mathrm{O}$ autor retrata com essa passagem a necessidade que as pessoas precisam de educação para que possam aprender a reconhecer os seus direitos e a lutar por eles.

Encontra-se na falta de educação das pessoas, mais uma falha estatal que ocorre desde a época em que o livro foi escrito e perdura até os dias atuais; sendo essa a forma mais 
comum de se manter a sociedade refém do Estado, por ela não compreender bem quais são os seus direitos e não possuir armas que lhes dê condições de lutar por ele.

Graciliano expôs em "Vidas Secas" muitos problemas do século passado, que mais parece que foram retratados os problemas dos dias atuais. Não houve libertação da seca, da segregação social, do analfabetismo, nem muitos menos do abuso de poder praticado pela maioria das autoridades. É intrigante observar como tempo passou e como ainda se encontram pessoas que vivem na mesma medíocre realidade. O Estado lembra de punir severamente, mas esquece fácil de cumprir o seu papel de governar pelo povo e garantir condições dignas de sobrevivência para todos.

\section{A POSTURA DO "SOLDADO AMARELO" E A RELAÇÃO COM A POLÍTICA CRIMINAL ADOTADA ATUALMENTE}

O Soldado Amarelo representa, no enredo de Vidas Secas, a polícia do vilarejo que fica próximo à fazenda que Fabiano e sua família passaram a viver. Mesmo sendo o seu papel resguardar a segurança dos habitantes deste vilarejo, o Soldado Amarelo é apresentado no livro como sendo o causador da confusão com Fabiano por motivo fútil, no capítulo "Cadeia". Esse fato remete a um Estado opressor que abusa dos poderes para oprimir os seus cidadãos e que utiliza os artifícios que possui para puni-los, severamente, por coisas que nem tinham a intenção de cometer, se não fossem provocados.

No capítulo "Cadeia", o autor conta que Fabiano sai da fazenda para comprar coisas que faltam na casa, a pedido de Sinhá Vitória e fica muito revoltado por achar que todos os comerciantes da feira estão lhe enganando. Após as compras, ele faz uma pausa para descansar na bodega do seu Inácio, toma uma lapada de pinga e senta na calçada. É nessa hora que chega o Soldado Amarelo e chama Fabiano para jogar e o mesmo, em seus pensamentos, ressalta que por muito respeito e por ser muito obediente a farda do soldado aceita, ainda que ficasse preocupado com o que Sinhá Vitória iria pensar. Em pouco tempo eles perderam o jogo e Fabiano se levantou da mesa furioso por ter feito algo alheio ao seu desejo e pelo seu achar ter se concretizado, pois, sabia ele, desde o inicio, que iria perder e que seria muito criticado por Sinhá Vitória.

Já no caminho para a fazenda, Fabiano sente um empurrão e só depois se dá conta de que é o soldado amarelo que o agredia, por ele ter saído da bodega sem se despedir. Fabiano pensa em revidar o empurrão, mas entende que na cidade não era o lugar dele e não faz nada com o soldado, apenas diz que ele não tem o direito de fazer aquilo com um inocente que não 
tem culpa dele ter perdido o jogo. O soldado, cheio de razão, pisa no pé de Fabiano durante um bom tempo, até que ele se aborrece e insulta a mãe do soldado amarelo que imediatamente se aproveita para proferir voz de prisão e encaminhá-lo para a cadeia. Na cadeia, Fabiano ainda é vítima de agressões físicas e passa a noite lá, sem poder dá notícia a sua família.

À medida que se analisa esse episódio do livro, percebe-se como o autor retratou a postura do Estado na época em que escreveu a obra, ou seja, um período ditatorial no qual a razão era apenas do Estado que, por ter um conceito abstrato, se personificava nos seus agentes, representados, nesse caso, pelo Soldado Amarelo.

Essa análise causa admiração ao destacar as inúmeras semelhanças com a forma de agir do Estado contemporâneo, que mesmo possuindo conquistas do nível de uma Constituição Cidadã, ainda se vivencia essa realidade sem nenhuma observância aos princípios que defendem os Direitos Humanos. É nítido perceber, na análise da realidade brasileira, o fato de que mesmo decorridos 76 anos da publicação desta obra, o Estado ainda abusa do poder e aplica, indscriminamdamente, a pena privativa de liberdade caracterizando a sua adoção pela política pública do Direito Penal Máximo que defende a todo custo, o encarceramento como principal forma de resolver o cometimento de qualquer que seja o tipo de infração, que no caso de Fabiano se constituiu no desacato autoridade.

A política pública do Direito Penal Máximo exalta o valor e prega a unicidade da criminalização primária que é definida por Masson (2013) como sendo o ato e o efeito de sancionar uma lei primária material, que incrimina ou permite a punição de determinadas pessoas. Essa definição ressalta ainda mais a interpretação da lei em sua literalidade, despida dos valores e das circunstâncias que possam amenizar a punição ou até tornar insignificante algumas condutas, como bem defendem os princípios que nortearam a construção de outro ramo da política pública: o Direito Penal Mínimo.

Dentro dessa vertente de punibilidade máxima Fabiano se encaixa na criminalização secundária que é, para Masson (2013) a ação punitiva sobre pessoas concretas, pois é comum observar órgãos do Estado atribuírem a um indivíduo o ato primariamente criminalizado, sobre ele recaindo a persecução penal. São características da criminalização secundária, definidas por Zaffaroni (2002), a seletividade e a vulnerabilidade por entender que há forte influência de ser o poder punitivo exercido principalmente sobre pessoas escolhidas em face de sua fragilidade, a exemplo de moradores de rua, prostitutas; e Fabiano se encaixa perfeitamente nesse perfil de vulnerabilidade.

Por ser um retirante, sem formação escolar, sem inserção na sociedade, Fabiano se encontra completamente vulnerável e se encaixando no perfil do criminoso que ao se expor, é 
punido pelo autoritarismo estatal, representado pelo Soldado Amarelo. Se adentrarmos em uma análise bem prática, podemos reconhecer que se fosse qualquer outro cidadão da vila, com o mínimo de educação e que sua figura fosse respeitada, com certeza o soldado não teria o atacado, nem muito menos restringido a sua liberdade. Isso acontece devido ao caráter de seletividade do Direito Penal que seleciona o indivíduo a ser punido, mesmo tendo dois ou mais cometido a mesma conduta.

O perfil que se encaixa no estereótipo de criminoso, por ser tão divulgado pela mídia, desenvolveu o medo da sociedade e isso acarreta o desvio de finalidade do Direito Penal, que antes era recriminar condutas e passou a se constituir na punição de características de vida, por decidir punir, ou não, o cidadão pelo que ele é, ou representa, e não pela conduta delituosa que ele veio a praticar. É o lamentável direito penal de autor ainda (e sempre!) em ação.

\section{CONCLUSÃO}

Considerando as mais diversas políticas criminais analisadas, observou-se que as perspectivas do Direito Penal Máximo não produzem efeitos adequados, além de se apresentarem perigosamente aproximados das medidas totalitaristas. Diante de todas as formas alternativas de punição já desenvolvidas, não é possível insistir em optar pelo retrocesso. Não se pode, em pleno século XXI, enxergar o ser humano como representante do mal, apenas pelas características físicas e psicológicas que ele possui, tampouco pelas condições da vida que apresenta.

O principal ponto de distinção entre os homens, quando se trata de punição, deve ser a infração por eles cometida, aliada da minuciosa análise das circunstâncias que os levaram a cometer tal ato, sendo assim, individualizada abordagem no caso concreto, prepara-se a decisão de aplicação da pena, conferindo ao magistrado meios para agir com justiça.

É preciso a consciência da sociedade imediatista, que pede respostas extremas, por não entender que a principal causa da mendicância, do envolvimento com drogas, do roubo, do furto é a falta de equidade na distribuição da renda do país, sendo os marginalizados obrigados a conviver com a vida tranquila dos abastados. E mais, nem sempre os que vivem em tal situação de desigualdade optam pelo crime, mas são estigmatizados e humilhados pelo abuso de poder das autoridades que se sentem na razão em todas as atitudes que lhe convém.

Fabiano é um exemplo literário do complexo problema da máxima inserção estatal e da desnecessidade de muitas prisões que acabam comprometendo a liberdade de pessoas, sem, contudo produzir nenhum efeito positivo. A ideia de o Estado interferir somente quando 
necessário, favorece a construção de uma sociedade mais justa e harmoniosa, porque baseado em um Direito Penal de equilíbrio, que refletirá coerção mínima, mas eficaz. O sistema penal brasileiro precisa se livrar da política da quantidade e trabalhar em prol da qualidade de aplicação da lei propiciando a determinação de resultados eficientes com menos riscos de estigmatizar cidadãos e de produzir reincidência.

\section{REFERÊNCIAS}

BARATTA, Alessandro. Criminologia y sistema penal. v. 1. Montevideu: B de F, 2004.

BAUMAN, Zygmunt. Globalização: as consequências humanas. Trad: PENCHEL, Marcus. Rio de Janeiro: Jorge Zahar, 1999.

BRASIL, Constituição. (1998). Manuais de Legislação Atlas. Alexandre de Moraes (org.). 35 ed. São Paulo: Atlas, 2015.

Lei n $^{\circ}$ 9.099/95, de 26 de setembro de 1955. Dispõe sobre os Juizados Especiais

Cíveis e Criminais e dá outras providências. Disponível em: $<$ http://www.planalto.gov.br /CCivil_03/ leis/L9099.htm>. Acesso em: 20 mai. 2014.

. Lei $\mathrm{n}^{\circ}$ 9.714/98, de 25 de dezembro de 1998. Altera os dispositivos do Decreto-Lei $\overline{\mathbf{n}^{\circ} 2.848}$, de 7 de dezembro de 1840- Código Penal (Lei de Penas Alternativas). Disponível em:< http://www.planalto. gov.br/ccivil_03/LEIS/L9714.htm>. Acesso em: 22 mai. 2014.

BIANCHINNI, Aline. A concepção minimalista do Direito Penal. In: Atualidades do Direito. Disponível em: <http://atualidadesdodireito.com.br/alicebianchini/2013/04/14/aconcepcao-minimalista-do-direito-penal/>. Acesso em: 28 de mai. 2013.

BIANCHINNI, Aline e GOMES, Luiz Flávio. Minimalismo garantista - reducionismo. In: Atualidades do Direito. Disponível em<: http://atualidadesdodireito.com.b r/alicebianchini/2013/05/26/minimalismo-garantista-reducionismo/ $\geq$. Acesso em: 26 de mai. 2013.

CALleGARI, André Luiz. O Princípio da Intervenção Mínima no Direito Penal. IBCcrim, $\mathrm{n}^{\circ} 70,1998$.

CALLEGARI, André Luis e WEBBER, Suelen. O Mito do punir mais é melhor: reflexos da expansão do Direito Penal fomentada pela mídia. In: IBCRIM. Disponível em:

http://www.ibccrim.org.br. Acesso em: 10 de abril de 2014.

COMISÍON INTERAMERICANA DE DERECHOS HUMANOS. Informe sobre el uso de la prisión preventiva en las Américas. 30 de dezembro de 2013. Disponível em: <http://www.oas.org/es/cidh/ppl/informes/pdfs/Informe-PP-2013-es.pdf>. Acesso em: $20 \mathrm{de}$ abr. 2014. 
DUARTE NETO, Júlio Gomes. O Direito Penal simbólico, o Direito Penal mínimo e a concretização do garantismo penal. In: Âmbito Jurídico, Rio Grande, XII, n. 66, jul 2009. Disponível em: <http://www.ambito-juridico.com.br/site/index.php?n_link=revista _artigos_leitura\&artigo_id=6154>. Acesso: em abr. 2014.

FERRAJOLI, Luigi. Direito e razão: teoria do garantismo penal. 2. ed. São Paulo: Revista dos Tribunais, 2006.

JESUS, Damásio Evangelista de. Sistema Penal Brasileiro: execução das penas no Brasil. Revista Consulex. Ano I, n.1, p.24-28, Janeiro de 1997.

MASSON, Cleber. Direito penal esquematizado. Parte geral, vol. 1, 7. ed. Rio de Janeiro: Forense; São Paulo: Método, 2013.

PAVARINI, Massimo. Entrevista concedida ao Jornal Folha de São Paulo em 31 de agosto de 2009 - Punir mais só piora e agrava a insegurança. Disponível em: <http://teoriadoestado.blogspot.com.br/2009_08_01_archive.html>. Acesso em: $10 \mathrm{de}$ abril de 2014.

WACQUANT, Löic. As prisões da miséria. Tradução por: Telles, André. Rio de Janeiro: Zahar, 2001.

ZAFFARONI, Eugenio Raúl. Derecho Penal. Parte General. 2. ed. Buenos Aires: Ediar, 2002. 